\title{
Four decades of sustainable groundwater management
}

An interview with Peter Kavounas, General Manager, Chino Basin Watermaster

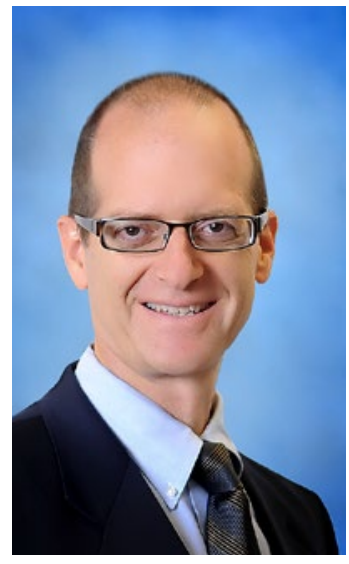

Peter Kavounas
$\mathrm{P}$

eter Kavounas is the General Manager of Chino Basin Watermaster, the nine-person entity created in 1978 by a state Superior Court adjudication judgment. The Watermaster is charged by the Court to sustainably manage groundwater in the 235-square-mile Chino Basin in San Bernardino, Riverside and Los Angeles counties.

Under the oversight of a board that represents the basin's groundwater users, Watermaster monitors groundwater extraction so that it does not exceed the basin's safe yield. In some ways, the roles and responsibilities of the Watermaster are similar to those of the groundwater sustainability agencies (GSAs) formed recently around the state under the Sustainable Groundwater Management Act.

California Agriculture spoke with Kavounas about the challenges that the Chino Basin Watermaster has faced and potential lessons that the agency's experience may offer for GSAs around the state as they prepare and implement groundwater sustainability plans (GSPs).

\section{What have been the key elements to making sustainable groundwater management work in the Chino Basin?}

I would say that the most important element has been willingness and commitment to cooperate on the part of the stakeholders, starting with the 1978 judgment, which was a stipulation, an agreement by all, that was ordered by the Court. The basin experienced overdraft, and everybody recognized that some kind of allocation of water rights made more sense.

The second element is continuously getting everybody to the point of awareness and agreement about the issues - that takes political leadership. It is essential for long-term success that the stakeholders stay engaged. You have to have management and oversight systems that adapt and evolve over time.

One of the most interesting things about the Chino Basin judgment was that it looked at what was likely to happen in the future, which was that agricultural use was likely to decrease and urban development was likely to expand, and provided for an orderly transfer of unused rights from agriculture to appropriators. So, it needs to be more than "let's just manage for what's happening to today." We have to ask whether and how cities and agriculture are likely to change, and plan for that.

\section{How has the management of the basin changed over the years to respond to changing conditions?}

The first step was to determine the safe yield in 1978 and adjust as the land use has changed. Also, the judgment ordered Watermaster to create an optimum basin management plan that drives data collection, better understanding of hydrology and water budget, development of water supply plans, storage management, and subsidence management. This plan was adopted in the year 2000 and has been actively implemented since.

In round numbers, the safe yield was originally set at 140,000 acre-feet per year; the overlying land owners' (agricultural and nonagricultural users) share is 90,000 , and the appropriators' share is 50,000 . Since then, because the basin has been so closely monitored and studied, our understanding has improved, particularly with respect to surface water-groundwater interactions. So, we are in the process of adopting a new safe yield of 135,000 acre-feet per year. That will mean that the appropriators' share drops from 50,000 to 45,000 acre-feet per year.

One of the reasons the safe yield has dropped is that, in the Chino Basin, land use has completely reversed. In 1978, more than $70 \%$ of the land overlying the groundwater basin was actively farmed. Now more than $70 \%$ of it is developed. Land has been paved over, stream channels have been lined with concrete - so we have less recharge from percolation. Because we have the advantage of decades of extensive data collection and very robust computer simulations, we can model how various scenarios of future land-use changes would affect recharge rates and the safe yield.

However, communicating this reduction in the safe yield has been hard - why it is happening, what methods we used to determine what the new safe yield should be. Our lesson learned is that it can be hard to communicate about groundwater models and other technical tools. We have decided that we are going to re-evaluate the safe yield every 10 years - and to address the issue of communication, we have already made clear to the basin water users exactly which methods are going to be used.

\section{How are conflicts among water users resolved in the Chino Basin?}

Traditionally, conflicts among users are resolved through discussion and negotiation, and on occasion 
litigation. In case there is a difference of opinion among users or with Watermaster about the judgment, the user can be in front of the judge within 30 days. There's a very appealing cleanliness to that. The Court is not affected by politics, and the procedures that have to be followed are clear.

\section{What are the most important lessons you've learned about governing a groundwater management agency?}

When I've been invited to speak on panels about SGMA implementation, the point I've made is that GSAs will be called on to produce GSPs, and many GSAs will hire staff to do that, as well as technical and legal consultants. Two points about that:

It's really critical for the governing members of the agency (the board members, the people empowered to make decisions) to be actively engaged in the issues and decisions. It shouldn't be treated as just another committee assignment. Also, the issues - technical, legal and political - are so complex that it can take a year or two for a new board member to get up to speed. So the people appointed to GSA boards should be given some stability - for instance, 5 -year terms that are renewable.

Second, is the relationship between the GSA board and GSA management and staff. Inevitably, the staff are going to have to come back and say to the board members, "you can't pump as much as you used to.” The staff can't be worried about the politics of that - simply giving the GSA unwelcome news should not be an offense. Groundwater management is a complicated problem - it has money, politics, all the dimensions. So it just has to be approached from a higher perspective.

\section{What are some innovative engineering solutions the Water- master has implemented?}

Chino Basin has had one engineer for 30 years. His understanding of the basin has become almost supernatural, and he's been able to come up with great solutions - for instance for salinity management.

Our basin is a tilted, flow-through basin. The basin naturally empties into its southwest corner, where it connects with the Santa Ana River. We have a lot of high-salinity groundwater in that part of the basin, and as that infiltrated in the river it was increasing the salinity for downstream users of Santa Ana River water - like the Orange County Water District.

We have implemented a groundwater desalination system in that portion of the basin. Two treatment plants - capacity of 40,000 acrefeet per year - remove the salts, and the water goes into the municipal supply systems of water providers in our basin.

The [Santa Ana] Regional Water Quality Control Board was so satisfied with that as an overall salinity control plan that it allowed using recycled water upstream for direct use in farming or groundwater recharge. Flows in the Santa Ana River have remained above the levels required in the adjudication of that river (an adjudication separate from the Chino Basin adjudication). And Orange County is grateful for the reduced salinity.

\section{Any closing thoughts?}

In the Chino Basin, we have a plan that we call the Optimum Basin Management Program. It really corresponds to a GSP — and, having seen it work, I'm a believer in SGMA. It will help the state advance to better groundwater management. Having said that, the ultimate goal is having the state look at water - surface water as well as groundwater - as a singular resource. There's a disconnect now. The existing projects - the State Water Project and the Central Valley Project are magnificent surface water projects. In the future, their operation will have to be very much integrated with sustainable groundwater management. We'll have to shift from sustainable groundwater management in every basin to sustainable water management statewide. CA

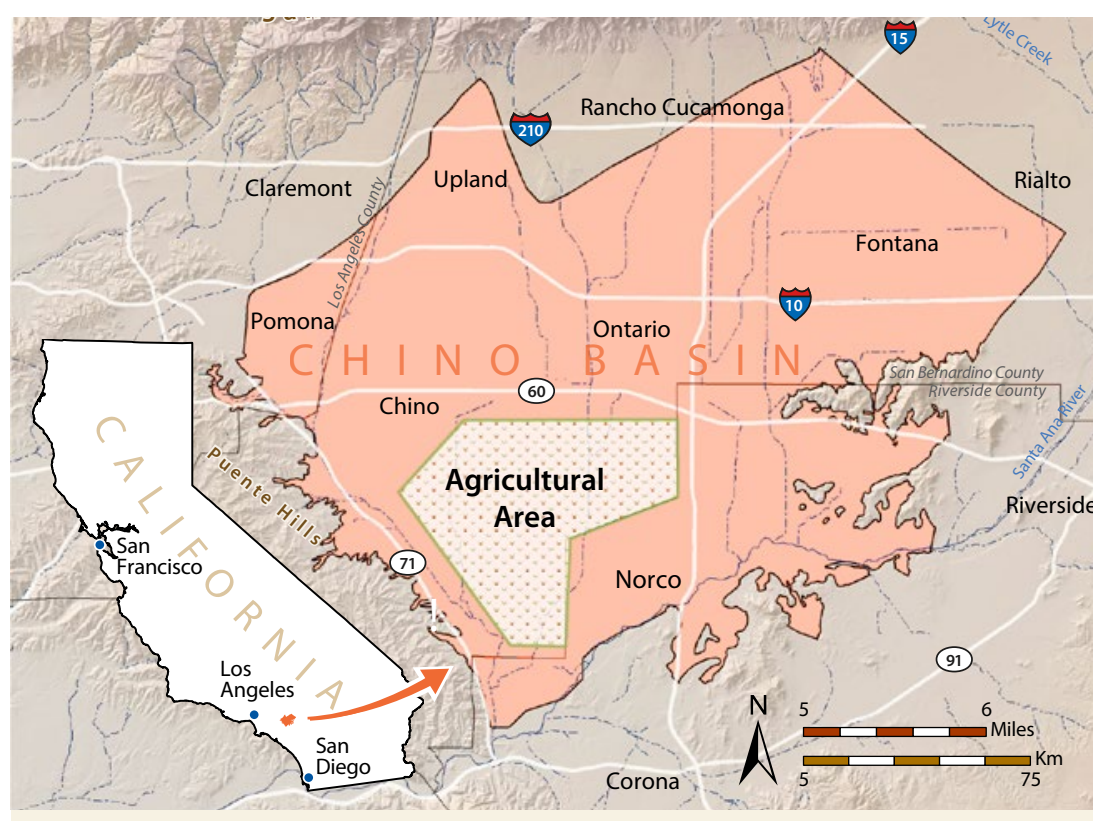

\section{The Chino Basin}

$\mathrm{O}$ ne of the largest groundwater basins in Southern California, the Chino Basin has a total storage capacity of roughly 6 million acre-feet. It currently holds about 5 million acre-feet of water. A substantial fraction of the basin's land area has shifted from agricultural to urban uses in recent decades, and the population continues to grow rapidly.

In the 1960s and '70s, the basin was being overpumped by more than 50,000 acre-feet per year, and water levels were dropping rapidly, as much as 7 feet per year in some areas. This chronic overdraft, combined with disagreements about groundwater allocation, led to adjudication hearings in San Bernardino Superior Court. The adjudication judgment issued in January 1978 established a safe yield of 140,000 acre-feet per year, allocated among overlying agricultural users (82,800 acre-feet per year); overlying nonagricultural users, mainly industry (7,366 acre-feet per year); and appropriative users, mainly municipal water suppliers (49,834 acre-feet per year).

Today, multiple approaches are used in the basin to increase the amount of water available without exceeding the safe yield including extensive groundwater recharge, water recycling (an increasingly important source of water for aquifer recharge), and desalination of groundwater (see article). 